(I) Botany for Children

By Lady Elphinstone. Pp. iv $+160+12$ plates. (London: Burns, Oates and Washbourne, Ltd., 1936.) 3s.6d.

(2) The Junior Gardener

By Harriet Price. Edited by Walter P. Wright. Pp. xii $+134+4$ plates. (London: J. M. Dent and Sons, Ltd., 1936.) 5s, net.

Tнat the child is indeed father of the man is being made increasingly obvious by the findings of modern psychological research. Any books, therefore, that aim at awakening in the developing child a sincere interest in a human activity so worth-while as the study and cultivation of plants are to be welcomed.

(1) In "Botany for Children" Lady Elphinstone revives a method of exposition very popular in the early part of last century. Jean, Mary and John, three inquiring children, learn about the characters of British plants from the lips of Dame Nature. The idea is, on the whole, well carried out; but the terms order, family, genus and species are used exceedingly loosely throughout the book. There are line block and coloured illustrations, the latter being arranged on a novel plan. The whole plant (including root) is shown against a background of its usual habitat, with a single fruit inset in one corner. On the whole, the paintings are accurate and give a fairly good impression of the plant.

(2) "The Junior Gardener" is written to help boys and girls who are taking up practical gardening for the first time, whether at home or at school. It tells in simple language how to carry out the various basic operations of gardening, and is fully illustrated with diagrams, drawings and coloured plates. The author has had personal experience of the problems of school gardening, and the chapter devoted to that subject should prove one of the most valuable in this well-planned and well-written book. J. S. L. G.

\section{Mercury Arc Rectifier Practice}

By F. C. Orchard. Pp. xi $+224+23$ plates. (London : Chapman and Hall, Ltd., 1935.) 15s. net.

DURING recent years there has been an increasing demand for machines and devices which will convert alternating currents into direct currents. Bulk supplies are usually given by alternating currents, but for some supply networks and for traction, direct currents are required. In these circumstances, devices such as machines called rotary converters, or stationary apparatus utilizing a physical property of electrolytes-electric ares, gas discharge tubes, etc.-are employed. The latter kinds of apparatus are called rectifiers and are of many types utilizing very different physical phenomena.

Most books on rectifiers devote much time to explaining the mathematical and physical theories on which the working of the various kinds of rectifiers is based. To the men who have to instal and operate the glass bulb and steel tank types of mercury are rectifiers used commercially for service on public supply systems, on railways and for industrial purposes generally, a book that will assist them in their daily work is required, and we think that they will find the book under notice a real help.

\section{Handbuch der Geophysik}

Herausgegeben von Prof. Dr. B. Gutenberg. Band I, Lief. 3 : Breitenschwankungen, von Prof. Walter D. Lambert; Theorie des irdischen Schwerefeldes, von Prof. E. A. Ansel. Pp. iv +501-730. Lief. 4 (Schluss des Bandes): Beobachtung der Schwerkraft; Die Lotabweichungen; Das Problem der Isostasie. Von Prof. Dr. W. Heiskanen. Pp. 731-970+xv. (Berlin : Gebrüder Borntraeger, 1934, 1936.) 31 gold marks each part.

Dr. LAMBERT's account of the variation of latitude is good, but a little too brief. Ansel on the theory of the gravitational field is mostly excellent, and so is Heiskanen on observations of gravity, pendulum deflections, and isostasy. Ansel claims to have detected an algebraical error in Darwin's theory of the figure of the earth, which affects the sign of the term in $\sin ^{2} 2 \varphi$, and he is apparently supported by Heiskanen. Here I think Darwin is right. One misses an account of the important work of de Sitter and his colleagues. Such omissions, however, are very few. These parts complete vol. I of the "Handbuch"; vols. 2 and 4 are already complete.

H. J.

\section{Lessons in Elementary Analysis}

By Dr. G. S. Mahajani. Second edition. Pp. xii + 264. (Poona: Aryabhushan Press, 1934.) n.p.

THIs book, first published in 1929, is designed to cover the analysis required for the bachelor's degree in most of the Indian universities. It deals mainly with the theory of number, in which there is an interesting examination of Dedekind's method; the theory of limits ; infinitesimals and continuity; the mean value, Maclaurin's and Taylor's theorems; Riemann integration; infinite integrals, uniform convergence and Fourier series. There is also a useful addendum on beta and gamma functions, power series, the application of Taylor's theorem to functions of several variables, Euler's theorems on homo. geneous functions and Young's theorem on implicit functions.

Each chapter contains a set of exercises for the student, and the text is thoroughly well written, the exposition of difficult points being exceptionally clear. The book should serve admirably the purpose for which it was written.

\section{Praktische Übungen zur Vererbungslehre:}

für Studierende, Ärzte und Lehrer. Von Prof. Dr. Günther Just. Zweite vermehrte und verbesserte Auflage. Teil I : Allgemeine Vererbungslehre. Pp. vi +137 . (Berlin : Julius Springer, 1935.) 6.90 gold marks.

Auтнолgr small, this compactly produced book contains a well-arranged exposition of methods in genetics. While mainly devoted to statistical methods, it includes measuring instruments, the technique of breeding Drosophila, and different types of mouse cages. The statistics deal with continuous and discontinuous variation, the binomial curve, correlation tables, back-crossing, sex-linked characters, the testing of Mendelian ratios, the $\chi^{2}$ test and other methods commonly used by geneticists. 